\title{
High red blood cell distribution width levels could increase the risk of hemorrhagic transformation after intravenous thrombolysis in acute ischemic stroke patients
}

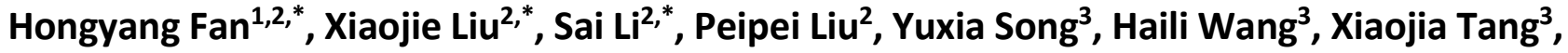 \\ Yuhan $\mathrm{Luo}^{3}$, Jun $\mathrm{Li}^{2}$, Yan Zhu ${ }^{2, \&}$, Yingzhu Chen ${ }^{2}$ \\ ${ }^{1}$ The Neurology Department, The Affiliated Lianyungang Hospital of Xuzhou Medical University, Lianyungang \\ 222002, Jiangsu, China \\ ${ }^{2}$ Department of Neurology, Clinical Medical College, Yangzhou University, Yangzhou 225001, Jiangsu, China \\ ${ }^{3}$ Dalian Medical University, Dalian 116000, Liaoning, China \\ *Equal contribution
}

Correspondence to: Yingzhu Chen, Yan Zhu; email: yzchendr@163.com, https://orcid.org/0000-0002-2110-236X; yzzyange@163.com, https://orcid.org/0000-0002-5351-7287.

Keywords: red blood cell distribution width, hemorrhagic transformation, intravenous thrombolysis, acute ischemic stroke Received: July 16, 2020

Accepted: May 12, 2021

Published: August 27, 2021

Copyright: (C) 2021 Fan et al. This is an open access article distributed under the terms of the Creative Commons Attribution License (CC BY 3.0), which permits unrestricted use, distribution, and reproduction in any medium, provided the original author and source are credited.

\section{ABSTRACT}

The association between the red blood cell distribution width (RDW) and hemorrhagic transformation (HT) after thrombolysis in acute ischemic stroke patients remains inconclusive. Our study aimed to assess whether high RDW levels are associated with the occurrence of HT after thrombolysis. Data were consecutively collected and retrospectively analyzed for stroke patients treated with thrombolysis between 1 January 2017 and 31 December 2019. The primary outcomes were the occurrence of HT and symptomatic HT. Among the 286 patients enrolled, 36 (12.6\%) developed HT and15 (5.2\%) were classified as symptomatic HT. Patients with high RDW levels were associated with a higher percentage of $H T$ and symptomatic $H T(P<0.05)$. The RDW levels in the HT and symptomatic HT groups were also greater compared with the no-HT group $(\mathrm{P}<0.001)$. Multivariable logistic regression analysis revealed that high RDW levels were independently associated with an increased risk of $\mathrm{HT}$ (adjusted odds ratio $2.5,95 \% \mathrm{Cl}, 1.74-3.83 \mathrm{P}<0.001$ ). In conclusion, we found that high RDW levels may be an independent predictor of $\mathrm{HT}$ in stroke patients after thrombolysis.

\section{INTRODUCTION}

Stroke is the leading cause of death and disabilityadjusted life-years in China [1]. Acute ischemic stroke (AIS) is the third most common cause of disability and mortality after cardiovascular diseases and cancer [2]. Reperfusion involving the administration of intravenous recombinant tissue plasminogen activator (rt-PA) for intravenous recombinant and endovascular thrombectomy (EVT) is associated with better neurological outcomes for AIS patients [3]. Hemorrhagic transformation (HT) is defined as bleeding into an area of ischemic brain after stroke, and appears in $10 \%$ to
$40 \%$ of acute ischemic stroke cases [4, 5], HT contributes to increased disability and mortality risk [6], and is believed to be either a part of the natural course of AIS or a common complication of intravenous thrombolytic therapy [7, 8]. Intravenous rt-PA therapy can induce or increase the risk for hemorrhagic transformation of ischemic lesions [9]. HT limits the use of intravenous thrombolysis (IVT), increases the risk of functional dependence and consequently decreases the benefit-risk ratio of IVT treatment.

The red blood cell distribution width (RDW) is a parameter that variability and heterogeneity in reflects red 
blood cell size [10]. RDW has been recognized as a potential independent risk factor for ischemic cerebrovascular disease. Several studies found that RDW can predict the occurrence, early mortality, 1-year survival, severity and functional outcomes of AIS patients [11-13]. A recent study reported that increased red cell distribution width is associated with an increased risk of HT in AIS patients [14]. However, previous reports have not thoroughly investigated the impact of RDW levels on hemorrhagic transformation in AIS patients who have undergone intravenous thrombolysis. Therefore, this study aimed to assess whether there was a relationship between RDW levels on admission and the development of HT after IVT, and to explore whether RDW on admission could be a biomarker of HT after IVT.

\section{RESULTS}

A total of 306 AIS patients treated with rt-PA within 4.5 $\mathrm{h}$ of symptom onset from Northern Jiangsu People's Hospital between 1 January 2017 and 31 December 2019 were selected to participate in this study. 20 patients were later excluded because of following reasons: malignant tumor $(\mathrm{n}=2)$, autoimmune diseases $(\mathrm{n}=3)$, lack of followup computed tomography scan $(\mathrm{n}=10)$, and 5 patients without RDW values. Consequently, data from 286 patients were eligible for the final analysis. The flowchart of the study is shown in Figure 1.
The mean age of the enrolled patients was $67.53 \pm 11.18$ years $(\mathrm{n}=286)$. There were $171(59.8 \%)$ men and 115 $(40.2 \%)$ women. A total of $36(12.6 \%)$ patients developed HT, and $15(5.2 \%)$ of HT patients were classified as symptomatic HT according to the Heidelberg Bleeding Classification. The RDW levels ranged from $11.3 \%$ to $20.7 \%$ with a median of $13.1 \%$.

Among the male patients, high RDW levels were associated with advanced age, longer onset-thrombolysis time, increased incidence of HT and symptomatic HT and low percentage of functional independence (all $\mathrm{P}<0.05$ ). In female patients, high RDW levels were associated with advanced age, high NIHSS score, longer onsetthrombolysis time, increased incidence of HT, and lower percentage of functional independence (all $\mathrm{P}<0.05$ ). Characteristics of patients were shown in Table 1.

Patients with asymptomatic hemorrhagic transformation were associated with advanced age $(\mathrm{P}=0.036)$, and a higher frequency of atrial fibrillation $(\mathrm{P}=0.02)$ compared to patients with symptomatic HT. Besides, patients with symptomatic HT were associated with high NIHSS on admission ( $\mathrm{P}<0.001)$, high RDW levels $(\mathrm{P}<0.001)$, low platelet counts $(\mathrm{P}=0.033)$ and low proportion of functional independence $(\mathrm{P}=0.002)$ compared to patients with asymptomatic HT and patients with no HT. As shown in Table 2.

306 AIS patients treated with r-tPA within $4.5 \mathrm{~h}$ of symptom onset were enrolled

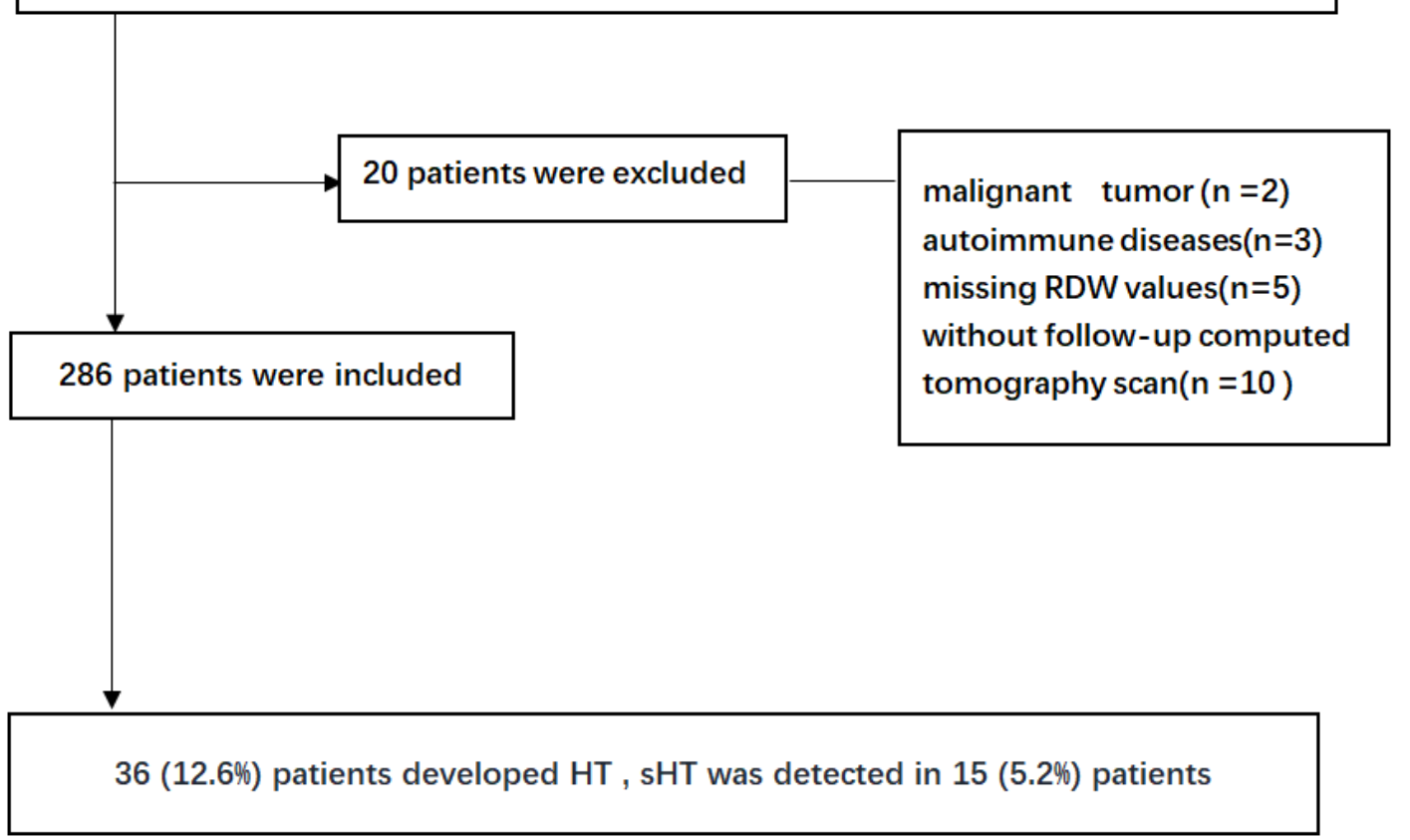

Figure 1. Flowchart of the study. 
Table 1. The baseline demographic and clinical characteristics of the patients according to RDW level based on gender.

\begin{tabular}{|c|c|c|c|c|c|c|}
\hline \multirow{2}{*}{ Characteristics } & \multicolumn{3}{|c|}{ Male (n= 171) } & \multicolumn{3}{|c|}{ Female $(n=115)$} \\
\hline & Tertile1 & Tertile2 & P-value & Tertile1 & Tertile2 & P-value \\
\hline No. $(\%)$ & $86(50.29 \%)$ & $85(49.71 \%)$ & & $58(50.43 \%)$ & $57(49.57 \%)$ & \\
\hline Age(years) & $65.15 \pm 10.86$ & $68.41 \pm 10.25$ & 0.043 & $66.71 \pm 11.81$ & $70.65 \pm 11.7$ & 0.118 \\
\hline Hypertension(n,\%) & $61(70.9 \%)$ & $63974.1 \%)$ & 0.732 & $35(60.3 \%)$ & $44(77.2 \%)$ & 0.07 \\
\hline Diabetes mellitus(n, \%) & $23(26.7 \%)$ & $15(17.6 \%)$ & 0.198 & $13(22.4 \%)$ & $14(24.6 \%)$ & 0.829 \\
\hline Hyperlipidemia(n, \%) & $46(54.8 \%)$ & $29(34.1 \%)$ & 0.009 & $25(43.1 \%)$ & $17(29.8 \%)$ & 0.176 \\
\hline Consumption of alcohol & $37(43 \%)$ & $32(37.6 \%)$ & 0.534 & $2(3.4 \%)$ & $0(0 \%)$ & 0.496 \\
\hline Smokers $(\mathrm{n}, \%)$ & $51(59.3 \%)$ & $41(48.2 \%)$ & 0.169 & $4(6.9 \%)$ & $2(3.5 \%)$ & 0.679 \\
\hline Previous stroke or TIA (n, \%) & $17(19.8 \%)$ & $11(12.9 \%)$ & 0.302 & $9(15.5 \%)$ & $6(10.5 \%)$ & 0.581 \\
\hline Atrial fibrillation(n, \%) & $11(12.8 \%)$ & $21(24.7 \%)$ & 0.052 & $13(22.4 \%)$ & $16(28.1 \%)$ & 0.525 \\
\hline Coronary artery disease (n, \%) & $7(8.1 \%)$ & $8(9.4 \%)$ & 0.794 & $5(8.6 \%)$ & $9(15.8 \%)$ & 0.268 \\
\hline Onset-thrombolysis time(minutes) & $173.5(134-210)$ & $190(150.5-242)$ & 0.048 & $207(153.75-240)$ & $180(130-225)$ & 0.029 \\
\hline NIHSS on admission & $5.99 \pm 5.78$ & $6.22 \pm 6.05$ & 0.607 & $5.41 \pm 5.8$ & $8.95 \pm 8.98$ & 0.019 \\
\hline Platelet counts $\left(x 10^{\wedge 9 / L}\right)$ & $186(157.75-222)$ & $174(151.5-212.5)$ & 0.224 & $187(154.75-232.75)$ & $178(136-214)$ & 0.123 \\
\hline BG on admission(mmol/L) & $7.16 \pm 2.98$ & $6.34 \pm 2.26$ & 0.077 & $6.69 \pm 2.42$ & $6.48 \pm 1.9$ & 0.963 \\
\hline $\mathrm{SBP}$ on admission $(\mathrm{mm} / \mathrm{Hg})$ & $151.3 \pm 21.72$ & $149.96 \pm 19.28$ & 0.593 & $158.26 \pm 25.18$ & $155.16 \pm 21.55$ & 0.497 \\
\hline $\mathrm{DBP}$ on admission $(\mathrm{mm} / \mathrm{Hg})$ & $87.19 \pm 14.75$ & $86.24 \pm 12.6$ & 0.734 & $85.76 \pm 13.34$ & $85.49 \pm 13.62$ & 0.906 \\
\hline $\mathrm{HT}(\mathrm{n}, \%)$ & $4(2.9 \%)$ & $32(21.9 \%)$ & $<0.001$ & $3(5.2 \%)$ & $13(22.8 \%)$ & 0.007 \\
\hline symptomatic HT(n, \%) & $2(1.4 \%)$ & $13(8.9 \%)$ & 0.005 & $1(1.7 \%)$ & $4(7 \%)$ & 0.206 \\
\hline Functional independence (FI) & $110(78.6 \%)$ & $85(58.2 \%)$ & $<0.001$ & $43(74.1 \%)$ & $28(49.1 \%)$ & 0.007 \\
\hline
\end{tabular}

TIA, Transient ischemic attack; NHISS, National Institutes of Health Stroke Scale; HT, hemorrhagic transformation; BG, blood glucose; SBP, systolic blood pressure; DBP, diastolic blood pressure; RDW, Red blood cell distribution width.

Table 2. The baseline demographic and clinical characteristics of the patients according to no HT asymptomatic HT or symptomatic HT.

\begin{tabular}{lcccc}
\hline Characteristics & No HT (250) & Asymptomatic HT (21) & Symptomatic HT (15) & P-value \\
\hline Age(years) & $66.89 \pm 11.25$ & $73.05 \pm 9.95$ & $70.53 \pm 9.49$ & 0.036 \\
Men(n, \%) & $151(60.4 \%)$ & $10(47.6 \%)$ & $10(66.7 \%)$ & 0.459 \\
Hypertension(n,\%) & $176(70.4 \%)$ & $14(66.7 \%)$ & $13(86.7 \%)$ & 0.399 \\
Diabetes mellitus(n, \%) & $55(22 \%)$ & $7(33.3 \%)$ & $3(20 \%)$ & 0.468 \\
Hyperlipidemia(n, \%) & $108(43.5 \%)$ & $4(19 \%)$ & $5(33.3 \%)$ & 0.073 \\
Consumption of alcohol & $65(26 \%)$ & $1(4.8 \%)$ & $5(33.3 \%)$ & 0.059 \\
Smokers(n,\%) & $89(35.6 \%)$ & $5(23.8 \%)$ & $4(26.7 \%)$ & 0.452 \\
Previous stroke or TIA (n, \%) & $38(15.2 \%)$ & $2(9.5 \%)$ & $3(20 \%)$ & 0.693 \\
Atrial fibrillation(n, \%) & $47(18.8 \%)$ & $9(42.9 \%)$ & $5(33.3 \%)$ & 0.02 \\
Coronary artery disease(n, \%) & $23(9.2 \%)$ & $5(23.8 \%)$ & $1(6.7 \%)$ & 0.111 \\
Onset-thrombolysis time(minutes) & $182.5(140-225)$ & $170(131.5-220)$ & $233(145-250)$ & 0.33 \\
NIHSS on admission & $4(2-7)$ & $9(3-14.5)$ & $12(7-23)$ & $<0.001$ \\
RDW & $13.06 \pm 0.92 \%$ & $14.28 \pm 0.73 \%$ & $14.55 \pm 2.04 \%$ & $<0.001$ \\
Platelet counts(x10^9/L) & $184(152-225)$ & $183(151-222)$ & $170(159-205)$ & 0.033 \\
BG on admission(mmol/L) & $6.68 \pm 2.48$ & $6.81 \pm 3.05$ & $6.55 \pm 1.49$ & 0.682 \\
SBP on admission (mm/Hg) & $154.13 \pm 22.13$ & $143.14 \pm 18.4$ & $149.53 \pm 19.11$ & 0.053 \\
DBP on admission(mm/Hg) & $86.33 \pm 13.35$ & $84.14 \pm 15.27$ & $88.4 \pm 15.28$ & 0.504 \\
Functional independence (FI) & $178(71.2 \%)$ & $13(61.9 \%)$ & $4(26.7 \%)$ & 0.002 \\
\hline
\end{tabular}

TIA, Transient ischemic attack; NHISS, National Institutes of Health Stroke Scale; HT, hemorrhagic transformation; BG, blood glucose; SBP, systolic blood pressure; DBP, diastolic blood pressure; RDW, Red blood cell distribution width. 
Table 3 shows the results of univariable logistic regression analyses that were used to determine the association between all the variables and HT or sHT. The results show that age, hyperlipidemia, AF, baseline NIHSS score, admission RDW levels, admission platelet count, and SBP were significantly associated with HT. When multivariable adjustment for potential confounders was carried out, the results showed that only the RDW levels and NHISS on admission were positively associated with hemorrhagic transformation (adjusted OR 2.5, 95\% CI (1.73-3.71, $\mathrm{P}<0.001$ : adjusted OR:1.08 95 \% CI: 1.03-1.14; $\mathrm{P}=0.002, \mathrm{P}$ $<0.001$; respectively). Every single point increase in NHISS increased the risk of hemorrhage transformation by $8 \%$ in AIS patients treated with intravenous thrombolysis. An increase in RDW levels by $1 \%$ increased the risk of hemorrhage transformation by 1.5 . Results from univariable regression analyses in this study showed that the effect of baseline NIHSS score, admission RDW level, platelet counts on the sHT in AIS patients treated by intravenous thrombolysis were significant (Table 3). Finally, the logistic model was statistically significant (Table 4). The RDW values were independently associated with a higher risk of developing symptomatic hemorrhagic transformation with an adjusted OR of 1.9(95 \% CI 1.37-2.93, P < $0.001)$. In addition, the NHISS score on admission (adjusted OR 1.1, 95 \% CI: 1.04-1.16; P = 0.001) was a significant predictor for sHT outcome.

Multiple-adjusted restricted cubic spline regression results showed that the pattern and magnitude between elevated RDW levels and the risk of HT and symptomatic HT (Figure 2). The adjusted OR of HT and symptomatic HT increased in a dose-dependent manner according to increasing levels of RDW. The odds ratios for HT were adjusted for age, atrial fibrillation, hyperlipidemia, NIHSS, platelet count and RDW, while those for symptomatic HT were adjusted for age NIHSS and RDW.

Stratified logistic regression analysis (Figure 3 ) used to identify variables, age $(<60$ versus $\geq 60$ ), sex (male versus female), atrial fibrillation, smoker, hypertension, consumption of alcohol, diabetes mellitus, hyperlipidemia, coronary artery disease and baseline NIHSS score $(<4$ versus $\geq 4)$, that modify the correlation between RDW levels and HT. Since all the P values for interaction were $>0.05$ and all the confidence intervals crossed the $\mathrm{OR}=1$ reference line, all tests for interactions were not significant.

\section{DISCUSSION}

To the best of our knowledge, this study provides the first comprehensive assessment of the relationship between RDW and HT or sHT after IVT in real-life situations. In this single-center retrospective study of AIS patients treated with IVT, we found that the incidence of HT and sHT was $12.6 \%$ and $5.2 \%$, respectively. In our study, RDW was significantly associated with hemorrhagic transformation and symptomatic hemorrhagic transformation in patients who underwent intravenous thrombolysis for acute ischemic stroke in models adjusted for age, AF, platelet count and NHISS on admission.

RDW is a simple, rapid, and widely available method for assessing RBC size heterogeneity, and it is calculated using the standard deviation (SD) of RBC volume. The known minimum and maximum values of RDW are $11 \%$ and $15 \%$, respectively [15]. Clinically, pathological increase in RDW is associated with anemia caused by iron, folic acid or vitamin B12 deficiency [16]. RDW values are also increased in some autoimmune diseases, myelodysplastic syndrome, hemolytic anemia, liver dysfunction, sickle cell disease, and blood transfusion therapy [17]. Recently, several studies have shown that increased RDW levels are associated with an increased risk of coronary heart disease, atrial fibrillation, carotid artery atherosclerosis, and ischemic stroke [18-22].

Several studies have focused on the association between RDW levels and functional outcomes after ischemic stroke. In previous studies based on stroke population, high RDW levels are an independent prognostic marker for 3-month functional outcome [23] and 30-day mortality [13]. A recent study found that RDW levels are significantly correlated with the severity of neurological function, which may be an important prognostic marker for AIS patients [24]. We also observed a significant association between RDW levels and 3-month functional outcomes. In our study, the patients with high RDW levels had lower rates of favorable functional outcome compared to patients with lower RDW levels in both genders (all $\mathrm{p}<0.05$ ).

In a recently published study, the risk of HT increased stepwise across RDW tertiles. Reperfusion therapy can modify the relationship between RDW and HT, with no significant association being observed between RDW and HT among patients who underwent reperfusion therapy [14]. However, reperfusion therapy includes IVT and EVT, yet the study did not specifically assess the relationship between RDW and HT in patients who underwent IVT. Therefore, EVT could have been a confounding factor in the study. As a result, the relationship between RDW and HT in patients that undergo IVT is unknown. Our study provides detailed information about hemorrhagic transformation after thrombolysis, an aspect that has not been investigated in 
Table 3. Univariable logistic regression analyses showing the associations of RDW level on admission and other baseline characteristics with HT; sHT.

\begin{tabular}{|c|c|c|c|c|c|c|}
\hline \multirow{2}{*}{ Variables } & \multicolumn{3}{|c|}{ Hemorrhagic transformation } & \multicolumn{3}{|c|}{ Symptomatic hemorrhagic transformation } \\
\hline & OR & $95 \% \mathrm{CI}$ & P-value & OR & $95 \% \mathrm{CI}$ & P-value \\
\hline Age & 1.048 & $1.011-1.087$ & 0.011 & 1.03 & $0.98-1.08$ & 0.286 \\
\hline $\operatorname{Men}(\mathrm{n}, \%)$ & 0.82 & $0.405-1.658$ & 0.58 & 1.37 & $0.46-4.1$ & 0.578 \\
\hline Hypertension(n,\%) & 0.793 & $0.356-1.768$ & 0.57 & 2.77 & $0.61-12.56$ & 0.186 \\
\hline Diabetes mellitus(n, \%) & 0.733 & $0.333-1.613$ & 0.441 & 0.84 & $0.23-3.08$ & 0.8 \\
\hline Hyperlipidemia(n, \%) & 2.314 & $1.045-5.125$ & 0.039 & 1.427 & $0.475-4.29$ & 0.527 \\
\hline Consumption of alcohol & 0.569 & $0.227-1.43$ & 0.23 & 1.55 & $0.51-4.7$ & 0.44 \\
\hline Smokers/ex-smokers(n,) & 0.603 & $0.272-1.339$ & 0.214 & 0.69 & $0.21-2.21$ & 0.53 \\
\hline Previous stroke or TIA (n, \%) & 0.9 & $0.329-2.46$ & 0.837 & 1.44 & $0.39-5.35$ & 0.58 \\
\hline Atrial fibrillation(n, \%) & 2.749 & $1.31-5.769$ & 0.008 & 1.92 & $0.63-5.84$ & 0.25 \\
\hline Coronary artery disease(n, \%) & 0.507 & $0.191-1.344$ & 0.172 & 1.61 & $0.2-12.74$ & 0.65 \\
\hline Onset-thrombolysis time(minutes) & 1.002 & 0.995-1.009 & 0.537 & 1.008 & $0.99-1.02$ & 0.14 \\
\hline NIHSS on admission & 1.104 & $1.058-1.152$ & $<0.001$ & 1.108 & $1.05-1.17$ & $<0.001$ \\
\hline RDW & 2.863 & $1.935-4.236$ & $<0.001$ & 2.002 & $1.37-2.93$ & $<0.001$ \\
\hline Platelet counts & 0.992 & $0.985-1$ & 0.038 & 2 & $1.37-2.92$ & $<0.001$ \\
\hline $\mathrm{BG}$ on $\operatorname{admission}(\mathrm{mmol} / \mathrm{L})$ & 1.004 & $0.873-1.155$ & 0.956 & 0.98 & $0.78-1.22$ & 0.83 \\
\hline $\mathrm{SBP}$ on admission $(\mathrm{mm} / \mathrm{Hg})$ & 0.982 & 0.966-0.999 & 0.034 & 0.99 & $0.97-1.02$ & 0.52 \\
\hline DBP on admission $(\mathrm{mm} / \mathrm{Hg})$ & 0.998 & $0.972-1.024$ & 0.865 & 1.01 & $0.97-1.05$ & 0.53 \\
\hline
\end{tabular}

TIA, Transient ischemic attack; NHISS, National Institutes of Health Stroke Scale; HT, hemorrhagic transformation; BG, blood glucose; SBP, systolic blood pressure; DBP, diastolic blood pressure; RDW, Red blood cell distribution width.

Table 4. Multivariable logistic regression analyses showing the associations of RDW level on admission with HT; sHT.

\begin{tabular}{lccccc}
\hline \multirow{2}{*}{ Variables } & \multicolumn{2}{c}{ HT } & & \multicolumn{2}{c}{ Symptomatic HT } \\
\cline { 2 - 3 } \cline { 5 - 6 } & Adjusted OR(95\%CI) & P-value & & Adjusted OR(95\%CI) & P-value \\
\hline RDW & $2.5(1.73-3.71)$ & $<0.001$ & & $1.9(1.37-2.93)$ & $<0.001$ \\
NIHSS on admission & $1.08(1.03-1.14)$ & 0.002 & & $1.1(1.04-1.16)$ & 0.001 \\
\hline
\end{tabular}

NHISS, National Institutes of Health Stroke Scale; HT, hemorrhagic transformation; RDW, Red blood cell distribution width.

previous studies to the best of our knowledge. We also found that the relationship between RDW and HT after IVT was independent of other known predictors of hemorrhagic transformation such as infarct volume, and NHISS on admission [3].

The rt-PA reperfusion process causes oxidative stress and release of proinflammatory cytokines leading to the blood-brain barrier (BBB) damage. Furthermore, the process of rt-PA itself can aggravate BBB disruption and increase the risk of HT [25]. A study carried out on animals showed that neuroinflammation results in ischemia-induced HT by inducing metalloproteinase -9 activation [26]. The study showed that oxidative stress mediates BBB damage via MMP activation in mice with copper/zinc-superoxide dismutase deficiency [27] and that treatment with the free radical scavenger significantly reduces rt-PA induced HT in embolic focal ischemia [28]. This indicates that oxidative stress plays an important role in BBB dysregulation during HT in the ischemic brain. Anoxia is also known to increase BBB permeability in cerebral capillaries [29].

The exact pathophysiological mechanism of the relationship between RDW and developing hemorrhagic transformation in patients who have undergone IVT is unknown. RDW levels have been reported to be associated with oxidative stress after $2 \mathrm{~h}$ of focal 
cerebral ischemia, with an increase in reactive oxygen species levels in microvessels and astrocytic endfeet [30]. Oxidative stress could increase RDW by inhibiting red blood cells production, increasing the size imbalance of red blood cells, and changing the deformability of cell membranes [31]. Elevated RDW levels are correlated with low oxygen exercise capacity [32], which could exacerbate HT development. Red blood cell distribution width is also correlated with hsCRP [33], and could be a potential biomarker of inflammation in stroke patients. AIS increases the secretion of inflammatory cytokines, inhibits genes expression involved in iron metabolism and hemoglobin synthesis and induces an increase in RDW levels [34]. An increase in RDW levels causes acute hypoxia, inducing EPO-driven erythropoiesis and a rapid increase in erythrocyte size variability [35]. Inadequate oxygen supply causes an increase in the blood-brain barrier permeability, leading to uncontrolled vasogenic edema, microvascular ischemia, or hemorrhagic transformation [36]. Therefore, RDW may be a marker for detecting hypoxia and oxidative stress. Future studies should systematically explore the mechanisms underlying the effects of RDW levels on HT.

A recent study found that there is a positive correlation between RDW and serum neuron-specific enolase levels. There is also an independent positive relationship between RDW and neuronal damage in AIS patients after adjusting for potential confounders [37]. A study by Lan Hong et al. demonstrated that increased baseline RDW is associated with poor collateral flow and increased final infarct volume in patients with large artery atherosclerosis stroke [38]. Since poor collateral flow and infarct volume have been known to cause hemorrhagic transformation [39], we believe that many factors could contributor to poor prognosis in AIS patients. These factors include some blood biomarkers associated with inflammation and oxidative stress that are readily available and can be included in the clinical scoring systems to predict clinical outcomes. Besides, many factors are changeable and can be targeted for therapeutic intervention. Based on our study results, we propose the use of RDW as a laboratory parameter for automatic routine hemogram detection. RDW can be used to predict hemorrhagic transformation in AIS patients with intravenous thrombolysis. Early triage, diagnosis, and management are compelling needs for the management and care of patients with cerebral ischemia.

Our study has some limitations. First, this is a singlecenter based retrospective analysis, with the limited data influencing the statistical significance of our conclusions. Therefore, further research in larger samples is needed to minimize the selection bias. Second, the numbers of HT and sHT cases were too small to perform an HT subtypes analysis further. Third, we lacked dynamic RDW data, that could reflect the
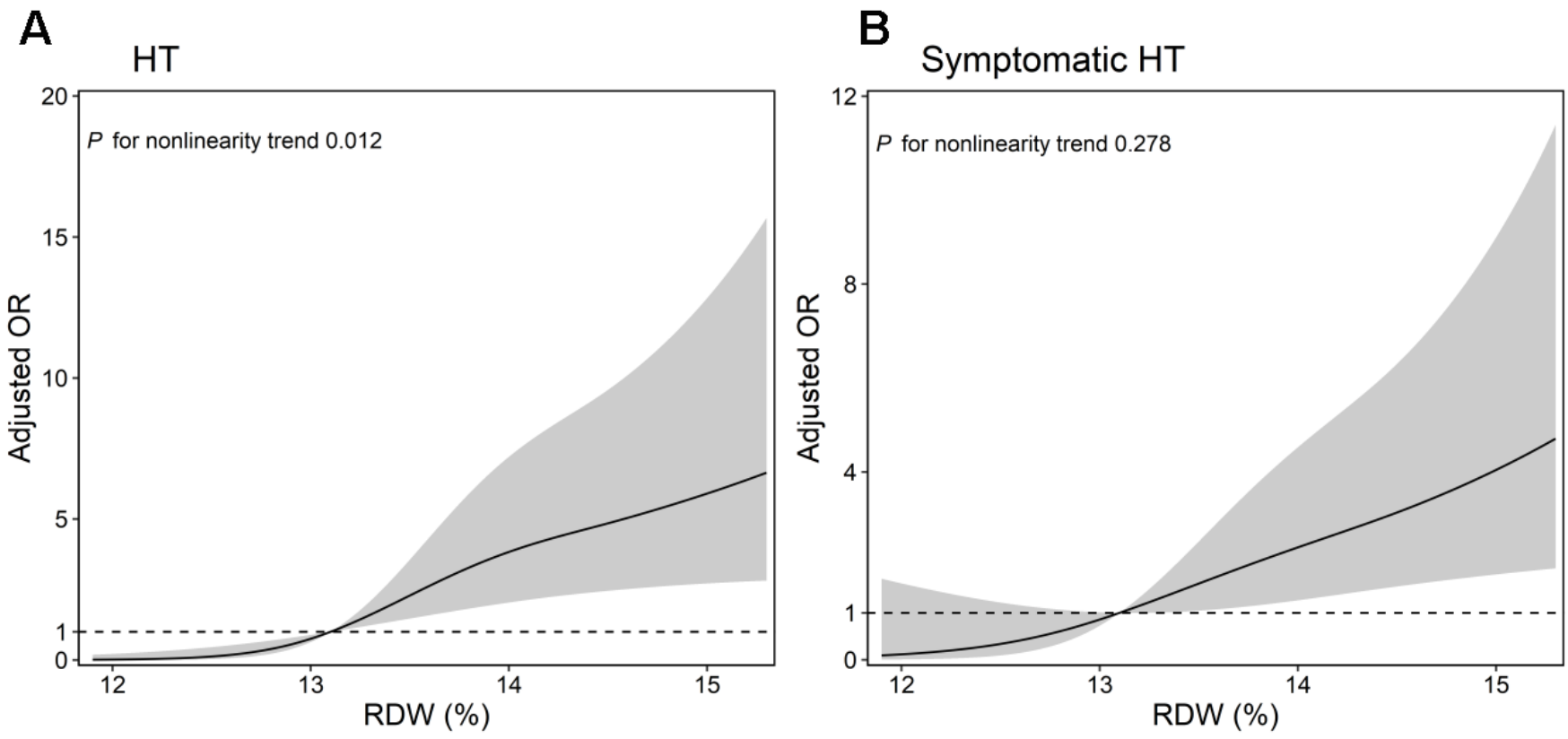

Figure 2. Multiple-adjusted restricted cubic spline regressions were used to analyze the association between RDW and risk of HT, (A) symptomatic HT (B) after IVT placed at three knots (at the 10th, 50th, 90th percentiles). The solid line represents adjusted odds ratios, while the shaded area represents $95 \%$ confidence intervals (Cl). Reference point for RDW was the median (13\%). RDW, Red cell distribution width; HT, hemorrhagic transformation. 
dynamic nature of the inflammatory state. These could be the focus of our future studies. The current analysis mainly explored the association between RDW and HT in IVT patients, and to assess the risk of HT due to RDW requires further work. Nevertheless, the strength of our study reported on baseline RDW levels in acute ischemic stroke patients treated with intravenous thrombolysis.
In summary, we found that high red blood cell distribution width levels could increase the risk of hemorrhagic transformation after IVT. We think that the association between RDW and hemorrhagic transformation in AIS patients treated with intravenous thrombolysis, could be due to the mechanism of reactive inflammation and oxidative stress state.

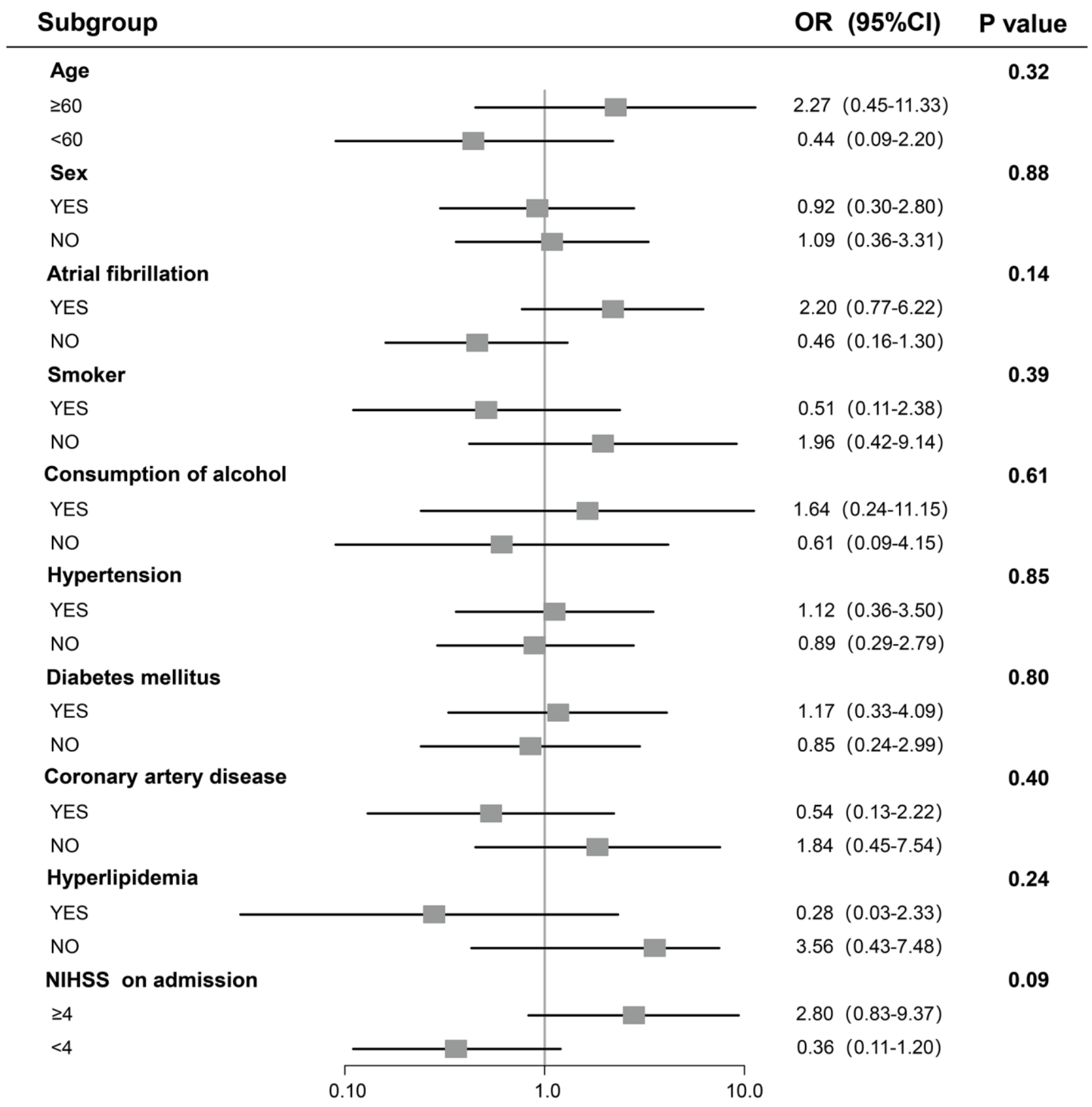

Figure 3. A Result of stratified logistic regression analysis testing association between RDW and hemorrhagic transformation. For subcategories, black squares represent OR, and horizontal lines indicate $95 \% \mathrm{Cl}$. For baseline NIHSS score, subgroups were dichotomized by median value. 


\section{MATERIALS AND METHODS}

Acute ischemic stroke patients who received rt-PA thrombolysis in Northern Jiangsu People's Hospital between 1 January 2017 and 31 December 2019 were consecutively recruited into this study. The inclusion criteria were as follows: (1) adults (age, $>18$ years), (2) The diagnosis of AIS based on World Health Organization criteria, and confirmed using magnetic resonance imaging (MRI), and (3) occurrence of stroke symptoms within 4.5 hours and the use of rt-PA therapy. (4) informed consent from patients or their relatives.

Exclusion criteria were listed as following: (1) history of craniocerebral operation, (2)contraindications of thrombolytic therapy including treatment with lowmolecular-weight heparin within 24h, active hemorrhage, aortic dissection, platelet count of $<100 \mathrm{x}$ $109 / \mathrm{L}$ in the peripheral blood; (3) anemia caused by previous diseases of the blood system and other causes; (4) autoimmune diseases, malignant tumors, congenital heart disease, hyperthyroidism, severe liver and kidney dysfunction; (5) a clear history of infection before admission; (6) history of blood transfusion and use of iron, folic acid and vitamin B12 within three months; (7) patients without sufficient data from laboratory examinations, or follow up information. Ethical approval for this study was obtained from the Ethics Committee of Northern Jiangsu People's Hospital. According to the declaration of Helsinki, written informed consent was obtained from each study participant.

\section{Treatment administration}

Intravenous rt-PA was used at a dose of $0.9 \mathrm{mg}$ per kilogram (maximum of $90 \mathrm{mg}$ ), with $10 \%$ of the total dose being used as an initial bolus within 1 minute and the remaining dose administered as a constant infusion for 60 minutes.

\section{Data collection}

Imaging findings, blood test results on admission, the National Institutes of Health Stroke Scale (NIHSS), (which was used to assess the severity of stroke on admission), onset-to-treatment time (OTT), demographic data and medical history including age, sex, and history of hypertension, diabetes mellitus, hyperlipidemia, smoking, atrial fibrillation, and previous stroke/TIA were collected. The initial RDW levels determined on admission before thrombolysis were also collected. Two researchers blinded to this study independently analyzed all the data, and a third researcher resolved any disagreement between the two researchers. Ethylenediaminetetraacetic acid (EDTAK2) anticoagulation vacuum tubes were used to collect $2 \mathrm{ml}$ of venous blood. The XE-5000 automatic blood analyzer of Sysmex Company was used for RDW analysis.

Head CT scans were repeated $24 \mathrm{~h}$ after treatment with IVT and another CT scan done immediately in case of clinical neurological deterioration to assess the existence of hemorrhagic transformation. Two neurologists experienced in neuroimaging who had not seen the patients' clinical data, independently evaluated the imaging findings.

\section{Classification criteria}

The definition of hemorrhagic transformation is that no hemorrhage was observed in the first cranial CT/MRI after cerebral infarction, but intracranial hemorrhage was observed on the second cranial CT/MRI examination [9]. CT scans were used to confirm and categorize hemorrhagic transformation. Symptomatic hemorrhagic transformation (sHT) was defined as an increase of the total NIHSS scores by more than 4 points compared with the score on admission according to the Heidelberg Bleeding Classification [40]. Smokers were defined as individuals who smoked at least one cigarette per day for at least a year and were current smokers. Alcohol consumption was defined as consuming 1 or more alcoholic drinks per day during the previous year. Functional independence was defined as a score of 0-2 points on the modified Rankin Scale, at three months of follow-up.

\section{Statistical analysis}

Continuous variables with normal distribution were expressed as mean \pm standard deviation, while variables that did not conform to normal distribution were represented by using median and interquartile range (IQR). Patients were divided into two groups based on gender since RDW levels had been reported to be higher in females than in males [41]. Student's t-test was used to analyze data that showed normal distribution, otherwise the data was analyzed using the Mann-Whitney U-test or Kruskal-Wallis H-test. On the other hand, the difference between categorical variables was analyzed using the Chi-square test or the Fishers accurate test. Variables with $\mathrm{P}<0.10$ in univariate analysis were candidates for stepwise forward multivariable logistic regression analysis to identify the independent predictors of outcome. In addition, we used restricted cubic splines with three knots placed at the 10th, 50th, and 90th percentiles to evaluate the pattern and magnitude of RDW with hemorrhagic transformation and symptomatic 
hemorrhagic transformation. Stratified logistic regression models were used to perform subgroup analyses. All statistical analyses were performed using Stata 15.1 (StataCorp LP, College Station, TX, USA), and R version 3.6.3 (R Foundation for Statistical Computing, Vienna, Austria). A two-tailed p-value of less than 0.05 was considered to be statistically significant.

\section{AUTHOR CONTRIBUTIONS}

Yingzhu Chen, Yan Zhu had full access to all of the data in the study and takes responsibility for the integrity of the data and the accuracy of the data analysis. Study concept, design: Hongyang Fan and Yan Zhu. Acquisition, analysis, or interpretation of data: Peipei Liu,Yuxia Song, Haili Wang, Xiaojia Tang, Yuhan Luo and Jun Li. Article drafting, and statistical analysis: Hongyang Fan and Yan Zhu. Study supervision: Yingzhu Chen, Yan Zhu. All authors read and approved the final manuscript.

\section{CONFLICTS OF INTEREST}

The authors declare that they have no conflicts of interest.

\section{FUNDING}

This work was supported by the "Six Talent Peaks" project of Jiangsu Province (No.WSW-246).

\section{Editorial note}

\& This corresponding author has a verified history of publications using a personal email address for correspondence.

\section{REFERENCES}

1. Zhou $M$, Wang $H$, Zeng $X$, Yin $P$, Zhu J, Chen W, Li X, Wang L, Wang L, Liu Y, Liu J, Zhang M, Qi J, et al. Mortality, morbidity, and risk factors in China and its provinces, 1990-2017: a systematic analysis for the Global Burden of Disease Study 2017. Lancet. 2019; 394:1145-58.

https://doi.org/10.1016/S0140-6736(19)30427-1

PMID:31248666

2. Lloyd-Jones D, Adams RJ, Brown TM, Carnethon M, Dai S, De Simone G, Ferguson TB, Ford E, Furie K, Gillespie C, Go A, Greenlund K, Haase N, et al, and WRITING GROUP MEMBERS, and American Heart Association Statistics Committee and Stroke Statistics Subcommittee. Heart disease and stroke statistics-2010 update: a report from the American Heart Association. Circulation. 2010; 121:e46-215.
https://doi.org/10.1161/CIRCULATIONAHA.109.19266 7 PMID:20019324

3. Jickling GC, Liu D, Stamova B, Ander BP, Zhan X, Lu A, Sharp FR. Hemorrhagic transformation after ischemic stroke in animals and humans. J Cereb Blood Flow Metab. 2014; 34:185-99.

https://doi.org/10.1038/jcbfm.2013.203

PMID:24281743

4. Beslow LA, Smith SE, Vossough A, Licht DJ, Kasner SE, Favilla CG, Halperin AR, Gordon DM, Jones Cl, Cucchiara AJ, Ichord RN. Hemorrhagic transformation of childhood arterial ischemic stroke. Stroke. 2011; 42:941-46.

https://doi.org/10.1161/STROKEAHA.110.604199 PMID:21350202

5. Terruso V, D’Amelio M, Di Benedetto N, Lupo I, Saia V, Famoso G, Mazzola MA, Aridon P, Sarno C, Ragonese P, Savettieri G. Frequency and determinants for hemorrhagic transformation of cerebral infarction. Neuroepidemiology. 2009; 33:261-65.

https://doi.org/10.1159/000229781

PMID:19641332

6. Berger C, Fiorelli M, Steiner T, Schäbitz WR, Bozzao L, Bluhmki E, Hacke W, von Kummer R. Hemorrhagic transformation of ischemic brain tissue: asymptomatic or symptomatic? Stroke. 2001; 32:1330-35.

https://doi.org/10.1161/01.str.32.6.1330

PMID:11387495

7. Nagaraja N, Tasneem N, Shaban A, Dandapat S, Ahmed $U$, Policeni B, Olalde $H$, Shim $H$, Samaniego EA, Pieper C, Ortega-Gutierrez S, Leira EC, Adams HP Jr. Cerebral Microbleeds are an Independent Predictor of Hemorrhagic Transformation Following Intravenous Alteplase Administration in Acute Ischemic Stroke. J Stroke Cerebrovasc Dis. 2018; 27:1403-11. https://doi.org/10.1016/i.jstrokecerebrovasdis.2017.1 2.044 PMID:29398533

8. Lees KR, Bluhmki E, von Kummer R, Brott TG, Toni $D$, Grotta JC, Albers GW, Kaste M, Marler JR, Hamilton SA, Tilley BC, Davis SM, Donnan GA, et al, and ECASS, ATLANTIS, NINDS and EPITHET rt-PA Study Group. Time to treatment with intravenous alteplase and outcome in stroke: an updated pooled analysis of ECASS, ATLANTIS, NINDS, and EPITHET trials. Lancet. 2010; 375:1695-703.

https://doi.org/10.1016/S0140-6736(10)60491-6 PMID:20472172

9. Álvarez-Sabín J, Maisterra O, Santamarina E, Kase CS. Factors influencing haemorrhagic transformation in ischaemic stroke. Lancet Neurol. 2013; 12:689-705. https://doi.org/10.1016/S1474-4422(13)70055-3 PMID:23726850 
10. Liu B, Chang R, Duan Z, Zhang X, Shen Y, Liu X, Wu J, Tuo $Y$, Luo J. The level of ROCK1 and ROCK2 in patients with pulmonary hypertension in plateau area. Sci Rep. 2018; 8:9356.

https://doi.org/10.1038/s41598-018-27321-4

PMID:29921927

11. Pinho J, Marques SA, Freitas E, Araújo J, Taveira M, Alves JN, Ferreira C. Red cell distribution width as a predictor of 1-year survival in ischemic stroke patients treated with intravenous thrombolysis. Thromb Res. 2018; 164:4-8.

https://doi.org/10.1016/j.thromres.2018.02.002 PMID:29438871

12. Song SY, Hua C, Dornbors D 3rd, Kang RJ, Zhao XX, Du $X$, He W, Ding YC, Meng R. Baseline Red Blood Cell Distribution Width as a Predictor of Stroke Occurrence and Outcome: A Comprehensive Meta-Analysis of 31 Studies. Front Neurol. 2019; 10:1237. https://doi.org/10.3389/fneur.2019.01237 PMID: $\underline{31849813}$

13. Lorente L, Martín MM, Abreu-González P, Pérez-Cejas A, González-Rivero AF, Ramos-Gómez L, Argueso M, Solé-Violán J, Cáceres JJ, Jiménez A, García-Marín V. Early Mortality of Brain Infarction Patients and Red Blood Cell Distribution Width. Brain Sci. 2020; 10:196. https://doi.org/10.3390/brainsci10040196 PMID:32224967

14. Wang C, Wang L, Zhong D, Deng L, Qiu S, Li Y, Liu M, Wu B. Association between Red Blood Cell Distribution Width and Hemorrhagic Transformation in Acute Ischemic Stroke Patients. Cerebrovasc Dis. 2019; 48:193-99.

https://doi.org/10.1159/000504742 PMID:31786566

15. Lippi G, Plebani M. Red blood cell distribution width (RDW) and human pathology. One size fits all. Clin Chem Lab Med. 2014; 52:1247-49.

https://doi.org/10.1515/cclm-2014-0585

PMID:24945432

16. Sultana GS, Haque SA, Sultana T, Ahmed AN. Value of red cell distribution width (RDW) and RBC indices in the detection of iron deficiency anemia. Mymensingh Med J. 2013; 22:370-76.

PMID:23715364

17. Sahli CA, Bibi A, Ouali F, Fredj SH, Dakhlaoui B, Othmani R, Laouini N, Jouini L, Ouenniche F, Siala H, Touhami I, Becher M, Fattoum S, et al. Red cell indices: differentiation between $\beta$-thalassemia trait and iron deficiency anemia and application to sickle-cell disease and sickle-cell thalassemia. Clin Chem Lab Med. 2013; 51:2115-24.

https://doi.org/10.1515/cclm-2013-0354

PMID:23800659
18. Li B, Liu S, Liu X, Fang J, Zhuang W. Association between red cell distribution width level and risk of stroke: A systematic review and meta-analysis of prospective studies. Medicine (Baltimore). 2020; 99:e19691.

https://doi.org/10.1097/MD.0000000000019691 PMID:32311945

19. Qian H, Luo Z, Xiao C, Chen J, Li D, Xu H, He P, Zhou X, Zhang $\mathrm{T}$, Min X. Red cell distribution width in coronary heart disease: prediction of restenosis and its relationship with inflammatory markers and lipids. Postgrad Med J. 2018; 94:489-94.

https://doi.org/10.1136/postgradmedj-2018-135806 PMID:30301834

20. Wonnerth A, Krychtiuk KA, Mayer FJ, Minar E, Wojta J, Schillinger $M$, Koppensteiner $R$, Hoke $M$. Red cell distribution width and mortality in carotid atherosclerosis. Eur J Clin Invest. 2016; 46:198-204. https://doi.org/10.1111/eci.12584 PMID:26709235

21. Adamsson Eryd S, Borné $Y$, Melander $O$, Persson $M$, Smith JG, Hedblad B, Engström G. Red blood cell distribution width is associated with incidence of atrial fibrillation. J Intern Med. 2014; 275:84-92. https://doi.org/10.1111/joim.12143 PMID:24112470

22. Lappegård J, Ellingsen TS, Skjelbakken T, Mathiesen EB, Njølstad I, Wilsgaard T, Brox J, Brækkan SK, Hansen JB. Red cell distribution width is associated with future risk of incident stroke. The Troms $\varnothing$ Study. Thromb Haemost. 2016; 115:126-34.

https://doi.org/10.1160/TH15-03-0234

PMID:26290352

23. Wang L, Wang C, Wu S, Li Y, Guo W, Liu M. Red blood cell distribution width is associated with mortality after acute ischemic stroke: a cohort study and systematic review. Ann Transl Med. 2020; 8:81.

https://doi.org/10.21037/atm.2019.12.142 PMID:32175374

24. Mohindra R, Mishra U, Mathew R, Negi NS. Red Cell Distribution Width (RDW) Index as a Predictor of Severity of Acute Ischemic Stroke: A Correlation Study. Adv J Emerg Med. 2019; 4:e24.

https://doi.org/10.22114/ajem.v0i0.257 PMID:32322792

25. Wang W, Li M, Chen Q, Wang J. Hemorrhagic Transformation after Tissue Plasminogen Activator Reperfusion Therapy for Ischemic Stroke: Mechanisms, Models, and Biomarkers. Mol Neurobiol. 2015; 52:1572-79.

https://doi.org/10.1007/s12035-014-8952-x PMID:25367883

26. del Zoppo GJ, Frankowski H, Gu YH, Osada T, Kanazawa M, Milner R, Wang X, Hosomi N, Mabuchi T, Koziol JA. 
Microglial cell activation is a source of metalloproteinase generation during hemorrhagic transformation. J Cereb Blood Flow Metab. 2012; 32:919-32.

https://doi.org/10.1038/jcbfm.2012.11

PMID:22354151

27. Switzer JA, Hess DC, Ergul A, Waller JL, Machado LS, Portik-Dobos V, Pettigrew LC, Clark WM, Fagan SC. Matrix metalloproteinase- 9 in an exploratory trial of intravenous minocycline for acute ischemic stroke. Stroke. 2011; 42:2633-35.

https://doi.org/10.1161/STROKEAHA.111.618215 PMID:21737808

28. Asahi M, Asahi K, Wang X, Lo EH. Reduction of tissue plasminogen activator-induced hemorrhage and brain injury by free radical spin trapping after embolic focal cerebral ischemia in rats. J Cereb Blood Flow Metab. 2000; 20:452-57.

https://doi.org/10.1097/00004647-200003000-00002 PMID:10724108

29. Lochhead JJ, McCaffrey G, Quigley CE, Finch J, DeMarco KM, Nametz N, Davis TP. Oxidative stress increases blood-brain barrier permeability and induces alterations in occludin during hypoxiareoxygenation. J Cereb Blood Flow Metab. 2010; 30:1625-36.

https://doi.org/10.1038/jcbfm.2010.29 PMID:20234382

30. Zhao Z, Liu T, Li J, Yang W, Liu E, Li G. Elevated red cell distribution width level is associated with oxidative stress and inflammation in a canine model of rapid atrial pacing. Int J Cardiol. 2014; 174:174-76.

https://doi.org/10.1016/j.ijcard.2014.03.189

PMID:24750719

31. Diederich L, Suvorava T, Sansone R, Keller TCS 4th, Barbarino F, Sutton TR, Kramer CM, Lückstädt W, Isakson BE, Gohlke H, Feelisch M, Kelm M, CorteseKrott MM. On the Effects of Reactive Oxygen Species and Nitric Oxide on Red Blood Cell Deformability. Front Physiol. 2018; 9:332.

https://doi.org/10.3389/fphys.2018.00332

PMID:29867516

32. Tomkiewicz-Pajak L, Plazak W, Kolcz J, Pajak J, Kopec G, Dluzniewska N, Olszowska M, Moryl-Bujakowska A, Podolec P. Iron deficiency and hematological changes in adult patients after Fontan operation. J Cardiol. 2014; 64:384-89.

https://doi.org/10.1016/j.jicc.2014.02.021

PMID:24698006

33. Lappé JM, Horne BD, Shah SH, May HT, Muhlestein JB, Lappé DL, Kfoury AG, Carlquist JF, Budge D, Alharethi R, Bair TL, Kraus WE, Anderson JL. Red cell distribution width, C-reactive protein, the complete blood count, and mortality in patients with coronary disease and a normal comparison population. Clin Chim Acta. 2011; 412:2094-99.

https://doi.org/10.1016/j.cca.2011.07.018

PMID:21821014

34. Osterholm EA, Georgieff MK. Chronic inflammation and iron metabolism. J Pediatr. 2015; 166:1351-7.e1.

https://doi.org/10.1016/i.jpeds.2015.01.017 PMID:25684086

35. Yčas JW, Horrow JC, Horne BD. Persistent increase in red cell size distribution width after acute diseases: $A$ biomarker of hypoxemia? Clin Chim Acta. 2015; 448:107-17.

https://doi.org/10.1016/i.cca.2015.05.021 PMID:26096256

36. Kanazawa M, Takahashi T, Nishizawa M, Shimohata T. Therapeutic Strategies to Attenuate Hemorrhagic Transformation After Tissue Plasminogen Activator Treatment for Acute Ischemic Stroke. J Atheroscler Thromb. 2017; 24:240-53. https://doi.org/10.5551/jat.RV16006 PMID:27980241

37. Hong RH, Zhu J, Li ZZ, Yuan J, Zhao P, Ding J, Fan QL, Yang J, Liu BG, Cai J, Zhu DS, Guan YT. Red blood cell distribution width is associated with neuronal damage in acute ischemic stroke. Aging (Albany NY). 2020; 12:9855-67.

https://doi.org/10.18632/aging.103250 PMID:32445553

38. Hong L, Fang K, Ling Y, Yang L, Cao W, Liu F, Li G, Parsons $M$, Cheng $X$, Dong $Q$. Red Blood Cell Distribution Width Is Associated with Collateral Flow and Final Infarct Volume in Acute Stroke with Large Artery Atherosclerosis. Semin Thromb Hemost. 2020; 46:502-06.

https://doi.org/10.1055/s-0039-3400257

PMID:31858514

39. Bang OY, Saver JL, Kim SJ, Kim GM, Chung CS, Ovbiagele B, Lee $\mathrm{KH}$, Liebeskind DS, and UCLASamsung Stroke Collaborators. Collateral flow averts hemorrhagic transformation after endovascular therapy for acute ischemic stroke. Stroke. 2011; 42:2235-39.

https://doi.org/10.1161/STROKEAHA.110.604603 PMID:21737798

40. von Kummer R, Broderick JP, Campbell BC, Demchuk A, Goyal M, Hill MD, Treurniet KM, Majoie CB, Marquering HA, Mazya MV, San Román L, Saver JL, Strbian D, et al. The Heidelberg Bleeding Classification: Classification of Bleeding Events After Ischemic Stroke and Reperfusion Therapy. Stroke. 2015; 46:2981-86. 
https://doi.org/10.1161/STROKEAHA.115.010049

PMID:26330447

41. Alis R, Fuster $O$, Rivera L, Romagnoli M, Vaya A. Influence of age and gender on red blood cell distribution width. Clin Chem Lab Med. 2015; 53:e25-28.

https://doi.org/10.1515/cclm-2014-0756

PMID:25153605 